\title{
God as interlocutor - real or imaginary? Prosodic markers of dialogue speech and expected efficacy in spoken prayer
}

\author{
Oliver Niebuhr ${ }^{1}$, Uffe Schjoedt ${ }^{2}$ \\ ${ }^{1}$ Centre of Industrial Electronics, Mads Clausen Institute, University of Southern Denmark \\ ${ }^{2}$ Institute of Culture and Society, Aarhus University \\ oniebuhr@mci.sdu.dk, us@cas.au.dk
}

\begin{abstract}
We analyze the phonetic correlates of petitionary prayer in 22 Christian practitioners. Our aim is to examine if praying is characterized by prosodic markers of dialogue speech and expected efficacy. Three similar conditions are compared; 1) requests to God, 2) requests to a human recipient, 3) requests to an imaginary person. We find that making requests to God is clearly distinguishable from making requests to both human and imaginary interlocutors. Requests to God are, unlike requests to an imaginary person, characterized by markers of dialogue speech (as opposed to monologue speech), including, a higher f0 level, a larger f0 range, and a slower speaking rate. In addition, requests to God differ from those made to both human and imaginary persons in markers of expected efficacy on the part of the speaker. These markers are related to a more careful speech production, including al-most complete lack of hesitations, more pauses, and a much longer speaking time.
\end{abstract}

Index Terms: prayer, theism, dialogue speech, prosody.

\section{Introduction}

Millions of Christians around the world pray to God on a regular basis. Yet, speaking to God is a peculiar socio-linguistic phenomenon. On the one hand, praying practitioners accept God as a real person, who listens and responds to requests. On the other hand, God is invisible and in most other social social respects clearly different from normal human interlocutors [1]. Phonetic analyses of spoken prayer are veritably non-existent. The notable exception is glossolalia, which many consider a special kind of prayer activity $[2,3,4]$.

However, unlike glossolalia in which the produced speech is a monologue originating from divine inspiration, most prayers are dialogue acts. That is, the practitioner directs his or her own speech output to God (thanks-giving, praise, petitions etc.), see [5]. God, at the opposite end of the speech chain [6], is believed to be listening and responding to one's requests. So, getting the message across to God is a critical aspect of Christian prayer. Yet, no study, to our knowledge, has described how the phonetic correlates of making requests to God compares to similar requests made to normal human interlocutors on the one hand and to purely imaginary interlocutors on the other. Is God, in phonetic terms, treated as a human interlocutor, as an imaginary interlocutor, or as something in between? Does the act of making wishes to someone vary phonetically, depending on the speaker's perception of the interlocutor's presence and power to make the wishes come true? In order to shed initial light on these questions, we put forward two hypotheses:
H1: For believers who perceive God to be listening, a phonetic prayer analysis is expected to reveal correlates of real dialogue-like speech. In terms of these correlates, praying should be similar to requests directed at a real human person, but dissimilar to requests directed at an imaginary person.

$\mathrm{H} 2$ : For believers, who perceive God to intervene and respond to one's requests, prayer is hypothesized to reveal markers of expected efficacy, reflected in the believer's effort to produce clear and correct speech. In this respect, prayers differ from requests directed at a real human person, who lacks the power to fulfill requests, as well as from requests directed at a purely imaginary person.

Regarding H1, studies on the phonetic and, in particular, prosodic differences between monologues and dialogues are scarce. One of the few available comparisons is made in the acoustic analysis of German questions and statements by [7], see [8] for a summary. Quite a few studies have looked at differences between read and spontaneous speech, though; and this comparison often coincides with the difference between monologues and dialogues. Yet other studies present differences between read and spontaneous dialogues (e.g., [9]), which we can then relate to contrastive analyses of read and spontaneous monologues $[10,11,12]$. The overall results patterns are not fully consistent across studies [13]. However, what crystallizes across studies is that, compared to spoken monologues, dialogue speech is characterized by a slower speaking rate as well as by a higher level and a larger range of the fundamental frequency or f0 (i.e. the lowest frequency of the produced speech signal that provides the acoustic basis for listeners perception of pitch and, thus, speech melody, [14]). Studies by [15] and [16], amongst others, also found that dialogues show significantly more silent pauses and hence shorter prosodic phrase durations than monologues ([17], see also [13]), or faked dialogues (without any addressee).

Regarding H2, we assume that expected prayer efficacy is reflected prosodically in a careful speech planning and hence should correlate with a reduced number of hesitations (i.e. filled pauses like "err", "um", "mmh", see [18]). At the same time, we expect the number of silent pauses to increase because they replace hesitations and because they were found to be "closely related with discourse and syntactic planning" efforts [19, p.52]. Moreover, we assume that expected prayer efficacy manifests itself in the believer's attempt to be as exhaustive and detailed as possible. Thus, all else being equal (including the speaking task) believers should produce more speech when praying to God than when talking to both real and purely imaginary persons. 


\section{Method}

The participants of this initial study represent a sub-sample of a larger and still growing dataset consisting of audio recordings of more than 90 participants with varying degrees of beliefs in God. All participants received written information about study purpose and procedure and signed a participant consent form prior to the study. The study was approved by the Science Ethics Committee of Central Region Denmark (\#272/2017) and registered at The Danish Data Protection Agency (\#2016-051-000001).

Twenty-two participants were included in the present analysis, 17 females and 5 males (average age 25 years, range 1935 years). They were selected solely based on their belief in God and in prayer efficacy. That is, all 22 participants were highly religious Christians who agreed to the following statement (in a questionnaire filled out in connection with the speech recordings): 'I believe that God responds to personal prayers'. The participants were recruited from evangelical Christian milieus of Aarhus, Denmark.

\subsection{Procedure and material}

All participants were exposed to the same procedure in which a brief contemplation phase (to prepare a list of requests) was followed by three conditions in which the same requests were made to different interlocutors (repeated measures). To characterize the act of making requests to a divine interlocutor vs a real human interlocutor vs an imaginary interlocutor, participants were instructed to make requests to: 1) God (divine interlocutor), 2) the human recipient (real interlocutor), and 3) Santa Claus (imaginary interlocutor). Unlike the conditions in which the participants made requests to the human recipient, requests made to God and Santa Claus were recorded in a private room. The requests made to the human were made such that speakers could directly address their interlocutor, who was instructed to sit in a relaxed and neutral listening posture in front of the participant. The human-recipient condition was always first, whereas the order of God and Santa Claus conditions were counterbalanced across participants.

After each request, participants were asked to rate their experience on two dimensions on a 9 -point scale $(0=$ not at all, $9=$ very strongly):

- To what extent did you feel the interlocutor's presence?

- To what extent did you feel the interlocutor listening?

After the recording session, participants were asked to complete a brief questionnaire, which included questions about prayer frequency, religious beliefs and a Danish translation of the Tellegen's absorption scale (TAS).

All speech recordings were recorded with a Zoom H4nPro by research assistants who also took the role of the human recipient in the initial real-interlocutor condition and who were carefully instructed in the procedure.

\subsection{Analyzed parameters}

The requests/prayers that the 22 speakers produced while addressing the three interlocutors, i.e. Human, God and Santa Claus, were acoustically analyzed in terms of six parameters:

- (1) f0 level (median, in Hz),

- (2) f0 range (semitones, number of octaves),

- (3) net speaking rate (syllables/s, disregarding pauses),
- (4) amount of speech produced (i.e. the total number of syllables),

- (5) pausing rate (number of silent pauses/s),

- (6) hesitation rate (number of hesitations/s, i.e. filled pauses like "err", "um", "mmh" etc.).

The latter parameter (6) was the only one that had to be double-checked manually by a phonetically trained listener, after it was extracted by an analysis script. The script looked for the typical phonetic characteristics of hesitations $[18,20,21]$, i.e. spectrally nearly stable sound sections of 200 ms or more that occur in between two pauses and show either a nearly flat $\mathrm{f} 0$ or a very limited $\mathrm{f} 0$ range at a lower level (for the given speaker). Double-checking was required as the script overlooked a number of very short hesitations and, in the opposite direction, it also misclassified a number of one-word utterances as hesitations.

The other five parameters (1)-(5) were automatically extracted from the recorded signals, using the scripts developed by de Looze [22] and de Jong and Wempe [23]. All analyses were conducted with PRAAT [24].

Only silent (i.e. non-speech) intervals longer than $200 \mathrm{~ms}$ counted as pauses in the acoustic analysis, as empirical studies show that shorter silent intervals often go unnoticed in speech perception $[25,26]$. Parameters (1)-(6) were analyzed on the basis of indi-vidual inter-pausal units. Then, a single grand mean or a total number count was formed across all interpausal units. In this way, each of the selected 22 speakers was characterized by 6 values per addressee condition (Human, God, Santa Claus), one value per parameter.

\subsection{Inferential statistics}

A one-way repeated-measures multivariate analysis of variance (RM-MANOVA) was conducted with the six parameters as dependent variables and Addressee as the three-level within-subjects variable. As additional dependent variables, we added the two ratings (0-9) provided by our participants for question $(1=$ interlocutor is present $)$ and question $(2=$ interlocutor is listening), see 2.1. Thus, there were 8 dependent variables in total. The 22 individual speakers were included as a covariate. For each dependent variable, multiple pairwise comparisons tests were performed between the three levels of the factor Addressee. A Sidak correction was used to adjust the significance levels to multiple testing.

\section{Results}

The RM-MANOVA resulted in a highly significant main effect of Addressee $\left(F[12,70]=8.744, p<0.001, \eta_{p}{ }^{2}=0.600\right)$. The multiple comparisons tests show that each dependent variable makes a significant contribution to this overall main effect through differences among the factor levels of Addressee, but with varying effect sizes. F0 range differences have the smallest effect size $\left(\eta_{\mathrm{p}}{ }^{2}=0.081\right)$ and pausing-rate differences the largest effect size $\left(\eta_{\mathrm{p}}{ }^{2}=0.676\right)$.

There was no significant main effect of Speaker nor a significant interaction of Speaker and Addressee. Thus, the 22 speakers showed a comparable and consistent speaking behavior in each of the three Addressee conditions. Note that this does not mean that there were no gender-specific prosodic differences $[27,28]$. However, these differences were statistically equivalent across all three Addressee conditions due to the study's within-subjects design. 
Based on the multiple comparisons tests, Figures 1-3 provide a descriptive results summary with significant differences between Addressee conditions being marked by asterisks $(<*>=\mathrm{p}<0.1 ;<* *>=\mathrm{p}<0.01 ;<* * *>=\mathrm{p}<0.001)$. With regard to the two speech melody characteristics, Figures 1(a)-(b) show that speakers used a significantly higher f0 level when addressing God than when addressing Santa Claus and the human recipient. The latter two addressee conditions did not differ from each other with respect to f0 level. The increase in fo level during prayers to God was similarly large for both male and female speakers, i.e. between 0.6-1.5 semitones. The f0 range shows differences between Santa Claus on the one hand and the human recipient and God on the other. When addressing the latter two interlocutors, speakers' melody range was almost half an octave larger. Specifically, it was almost 1.9 octaves large when addressing God as compared to only 1.4 octaves when addressing Santa Claus.
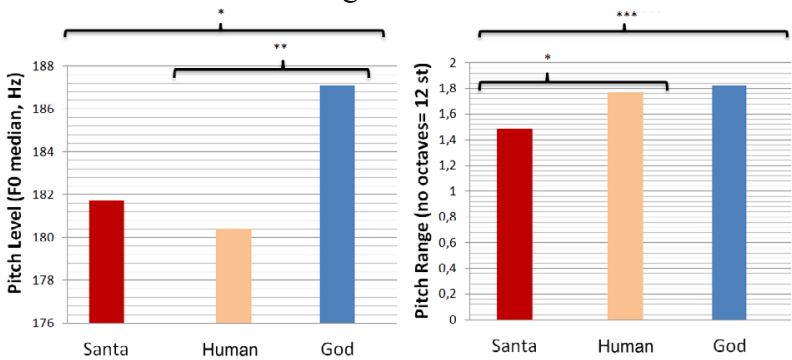

Figure 1: Mean values of (a) fo level and (b) fo range, $N=22$.

Figures 2(a)-(b) refer to the syllable-based parameters speaking rate and amount of speech produced. In Figure 2(a), it is shown that addressing God resulted in a lower speaking rate (i.e. fewer syllables per second) compared to the other two Addressee conditions, which did not differ from each other statistically. In terms of the amount of speech produced, i.e. Figure 2(b), the only significant difference was between God on the one hand and the Santa Claus and the human recipient on the other. Speakers produced almost twice as much speech (or twice as many syllables) when God was their interlocutor.
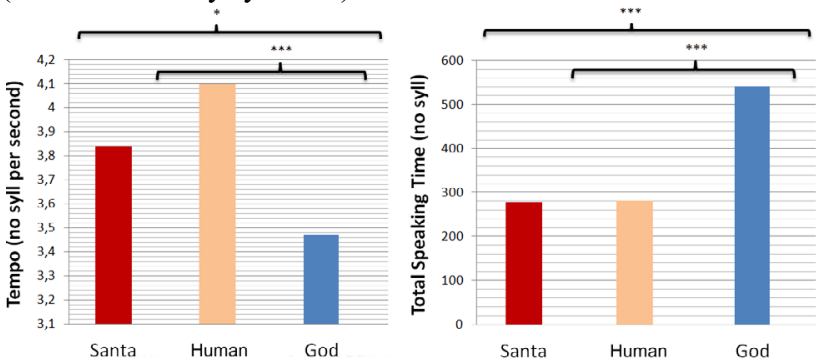

Figure 2: Mean values of (a) speaking rate and (b) total number of syllables, $N=22$.

Figures 3(a)-(b) summarize the results of the two frequency parameters, i.e. pausing rate and hesitation rate. Regarding the pausing rate, we see a clear and stepwise increase in the number of silent pauses per second across the three Addressee conditions from Santa Claus through the Experimenter to God. Compared to the Santa-Claus condition, speakers produced on average about one-fifth $(21.1 \%)$ more silent pauses in talking to a human interlocutor and almost one-third (31.6\%) more silent pauses in talking to God. The differences between all three Addressee conditions are significant.

The most striking Addressee-related difference, however, emerged for the hesitation rate. While speakers produced hesi- tations like "um", "err", "mmh" etc. on average every 6-7 seconds in talking to Santa Claus and the human recipient, hesitations almost completely disappeared when God was the interlocutor. This difference becomes even more impressive in absolute terms: All 22 speakers together realized only 32 hesitations while praying. In contrast, in the same speaking task with each of the other two addressees, they realized more than 240 hesitations. So, while E. Shriberg emphasized that "to 'errr' is human" [18], our results suggest that speakers are nevertheless reluctant to 'errr' in front of God. Rather, the pause-rate data suggests that speakers replaced their 'errr' by silent pauses in front of God. These and other points are discussed in more detail in the subsequent discussion section.
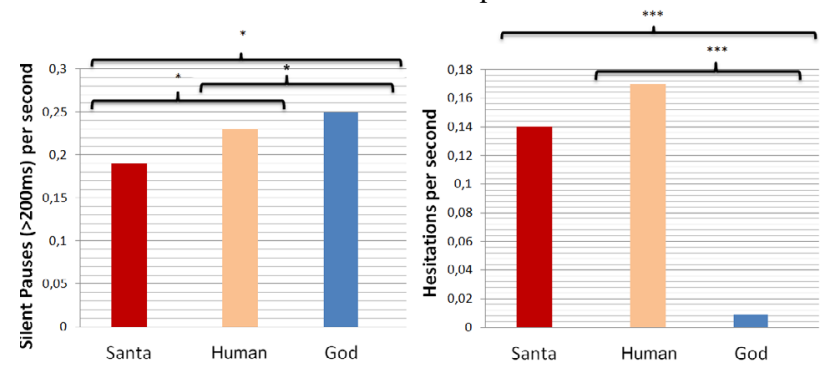

Figure 3: Mean values of (a) pausing rate and (b) hesitation rate (both in items per second), $N=22$.

Figure 4 summarizes the participants' subjective ratings of the extent to which they felt that the interlocutor was present and listening to their requests. Participants report clearly that God was present and listening to their requests. In fact, for our 22 highly religious Christians, God's perceived presence and listening did not differ statistically from the presence and listening of the real human recipient. Both God and the human recipient differ quite dramatically in these respects from Santa Claus whose felt presence and listening were close to 0 .

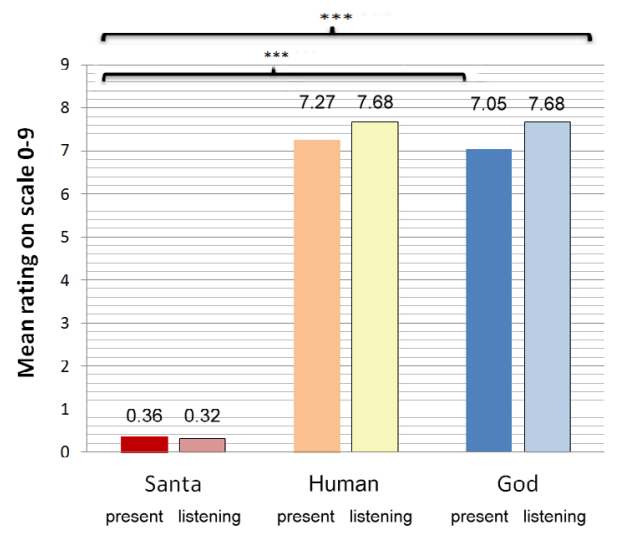

Figure 4: Mean scores of participants' subjective ratings on a 9-point scale, $N=22$.

\section{Discussion and Conclusion}

We find that making requests to God is clearly distinguishable from making requests to both real and imaginary interlocutors. Compared to an imaginary interlocutor (Santa Claus), making requests to God is characterized by using a higher fo level, a larger f0 range, and a slower speaking rate. This bundle of features can be interpreted as representing a change from a more monologue-like to a more dialogue-like way of speaking even though prayers are performed in a private room. Interpreting the prosodic patterns used in talking to God as indicators of 
dialogue is all the more plausible as God shares the higher and extended f0 patterns with the human recipient, whom the speakers addressed in a direct face-to-face conversation. We did find an unexpected difference in speaker tempo between God and the human recipient, though. The difference could reflect a relative uneasiness in the task of making requests to a complete stranger (the human recipient) so that the speakers rushed through their prepared list of requests.

In further support of the prosodic overlap between God and the human recipient, the speakers rated God to be just as present and listening as the human recipient. Thus, hypothesis $\mathrm{H} 1$ is supported by the present data. Among the 22 highly religious Christians we analyzed, praying indeed resembles requests directed at a real person, but dissimilar to requests directed at an imaginary person like Santa Claus.

Making requests to God is further characterized by an almost complete lack of hesitations, i.e. filled pauses. Results suggest that they were partly replaced by silent pauses. This finding is indicative of careful and planned speech production and, thus, points to the importance of prayer as a speech act. It matters what is said and how it is said because God is perceived as capable of fulfilling the requests made. The observed drop in hesitations is unique to prayer and was not present in similar requests made to the human recipient. Moreover, the practitioners embellished their requests with much more detail while praying, which causes a considerably longer speaking time in our data (total number of syllables) compared to both the Santa Claus and human recipient conditions. This adds to the assumption that the practitioners invested more effort in making requests to God. Overall, the almost complete lack of hesitations, their partial replacement by silent pauses, and the longer speaking time argue in favor of hypothesis H2. Prayers of highly religious Christians include markers of expected efficacy. They differ in this respect from requests directed at real as well as imaginary persons who, unlike God, lack the power to fulfill the prayer requests.

In summary, we suggest that the prosodic speech patterns observed in this study reflect participants' beliefs in God. Perceiving God as omnipresent and omnipotent creates the expectation that God is present, listening, and capable of responding to requests. This interpretation corresponds with findings on prayer obtained in other disciplines. Anthropological evidence shows that evangelical Christians often report that they feel God's presence when they pray, and that they often experience that God is responding to their prayers [1]. Indeed, the participants of the present study believed that God responds to their prayers, and their subjective ratings reveal that they felt that God was both present and listening to their requests.

Self-report measures like subjective ratings, however, are generally difficult to evaluate because they are subject to social psychological biases such as the social desirability effect (the tendency to respond in socially desirable ways). Selfreport measures on religious experience appear to be especially vulnerable to the social desirability effect [29]. To correlate self-reported experiences with more direct behavioral measures during religious practice is therefore crucial. The present study offers a direct measure: speech or, more specifically, speech prosody. Few other disciplines have attempted this. In cognitive neuroscience, it has been shown that making requests to God in silent prayer activates brain areas associated with social cognition (processing of other people's beliefs, intentions and desires). This supports the idea that talking to God resembles normal interpersonal interaction [30,31] and, thus, that God is perceived as a real interlocutor during prayer.
Our present prosodic findings are consistent with this evidence from neuroscience - and similarly direct and objective in nature. Yet, they are different because the prosody of spoken prayer may be determined by more than the practitioner's belief in an omnipresent and omnipotent God. Spoken prayer is also a specific genre into which children are socialized [32]. As such, spoken prayer is likely influenced by rehearsal and structures of collective speech acts. Such aspects of the prosody of prayer are beyond the scope of this study, but they clearly warrant more research. In this context, another insightful addressee condition to be added to future studies is, for example, Amazon's "Alexa", as it is somewhere in between an imaginary and a real human interlocutor, for example, in terms of embodiment, responsiveness, and efficacy.

The direction in which we currently continue our research on the prosody of prayer will provide further answers to this question of generalization, i.e. whether prosodic markers of dialogue and expected efficacy are general (socially learned) characteristics of the genre of prayer, or whether they are specific to highly religious practitioners, who believe in a present and reciprocating god. Do non-believers also adopt a more dialogue-like speech and produce fewer hesitations when confronted with the task of making requests to God? Are the observed characteristics only present in practitioners who strongly believe in prayer efficacy? Do people who self-identify as Christians but reject beliefs in a personal and reciprocating God, show similar prosodic features, or do they lack the prosodic markers of dialogue speech and expected efficacy?

The participants of the present study represent a small subsample of a larger dataset, which includes recordings from three groups, each represented by more than 30 speakers: 1) strong theists who believe that God responds to prayers, 2) weak theists who believe in God but not that He responds to prayers, and 3) atheists who deny the existence of any god. Combined with the repeated measures design reported here, this dataset will enable us to answer many of the research questions presented above. In addition, research on how (differently) people address real vs. imaginary persons probably also help study in more detail the cognitive development of children and some mental diseases [33,34].

In conclusion, although praying is a complex genre with many social-linguistic variables to consider beyond the effects of religious belief, our findings correspond with self-report evidence that praying believers experience God as a real interlocutor who is both listening and has the power to fulfill requests. This study is the first of its kind. More research is needed to clarify exactly how theistic beliefs influence the prosody and, more generally, the phonetics of spoken prayer. Surely, this question is complex with several types of prayer within Christianity, and a large variety of God beliefs and prayer practices beyond the Western Christian belief system. Nevertheless, we think this preliminary study represents a step toward understanding the complex phonetics of prayer.

\section{Acknowledgements}

The authors contributed equally to this paper. Uffe Schjoedt designed the study and organized the data collection. Oliver Niebuhr analyzed and interpreted the data. The study was supported financially by the Seed-funding program of the Interaction Minds Centre at Aarhus University, Denmark (grant \#24794). Both authors would like to thank our 22 recorded speakers as well as our research assistants, who conducted the study's recordings. 


\section{References}

[1] Luhrmann, T. M. (2012). When God talks back: Understanding the American evangelical relationship with God. Vintage.

[2] Goodman, F. D. (1969). Phonetic analysis of glossolalia in four cultural settings. Journal for the Scientific Study of Religion, 227-239.

[3] Samarin, W. J. (1973). Glossolalia as regressive speech. Language and Speech 16, 77-89.

[4] Spanos, N. P., Cross, W. P., Lepage, M., \& Coristine, M. (1986) Glossolalia as learned behavior: An experimental demonstration. Journal of abnormal psychology 95, 21.

[5] Spilka, B., \& Ladd, K. L. (2012). The psychology of prayer: A scientific approach. Guilford Press.

[6] Denes, P.B. \& E.N. Pinson (1992). The speech chain: the physics and biology of spoken language. New York: W. H. Freeman and Co.

[7] Niebuhr, O., Bergherr, J., Huth, S., Lill, C., \& Neuschulz, J. (2010). Intonationsfragen hinterfragt - Die Vielschichtigkeit der prosodischen Unterschiede zwischen Aussage- und Fragesätzen mit deklarativer Syntax. Zeitschrift für Dialektologie $u$. Linguistik 77, 304-346.

[8] Niebuhr, O. \& Michaud, A. (2012). Speech data acquisition The underestimated challenge. Kieler Arbeiten in Linguistik und Phonetik (KALIPHO) 3, 1-42.

[9] Bruce, G., and Touati, P. (1992). On the analysis of prosody in spontaneous speech with exemplification from Swedish and French. Speech Communication 11, 453-458.

[10] H.-J. Mixdorff \& H. Pfitzinger (2005). Analysing fundamental frequency contours and local speech rate in map task dialogs. Speech Communication 46, 310-325.

[11] Dellwo, V., A. Leeman, \& M.-J. Kolly (2015). The recognition of read and spontaneous speech in local vernacular: The case of Zurich German. Journal of Phonetics 48, 13-28.

[12] Blaauw, E. (1994). The contribution of prosodic boundary markers to the perceptual difference between read and spontaneous speech. Speech Communication 14, 359-375.

[13] Wagner, P. \& A. Windmann (2016). Acted and Spontaneous Conversational Prosody-Same or Different? Proc. 8th International Conference of Speech Prosody, Boston, USA, 1-5.

[14] Niebuhr, O., H. Reetz, J. Barnes \& A. Yu (2019). Perceptual effects of an on prosody. In: C. Gussenhoven, A. Chen (Eds), The handbook of prosody. Cambridge: Cambridge University Press.

[15] Hirschberg, J. (1995). Prosodic and other acoustic cues to speaking style in spontaneous and read speech. Proc. 13th International Congress of Phonetic Sciences, Stockholm, Sweden, 36-43.

[16] Strangert, E. (1993). Speaking style and pausing. PHONUM, Reports from the Department of Phonetics, University of Umea.

[17] Gustafson-Capkova, S. \& Megyesi, B. (2001). A Comparative Study of Pauses in Dialogues and Read Speech. Proc. 2nd Eurospeech Conference, Aalborg, Denmark, 931-935.

[18] Shriberg, Elizabeth (2001): To 'errr' is human: Ecology and Acoustics of Speech Disfluencies. Journal of the International Phonetics Association 31, 153-169.

[19] Rose, R. (2017). Silent and filled pauses and speech planning in first and second language production. Proc. DiSS 2017. Stockholm Sweden, 49-52.

[20] Braun, A. \& A. Rosin (2015). On the speaker-specificity of hesitation markers Proc. 18th International Congress of Phonetic Sciences, Glasgow, UK, 731-734.

[21] Duez, D. (2001). Acoustico-phonetic characteristics of filled pauses in spontaneous French speech: Preliminary Results. Proc. Disfluency in Spontaneous Speech (DiSS'01), Edinburgh, UK, 41-44.

[22] De Looze, C. \& Hirst, D.J. (2008). Detecting changes in key and range for the automatic modelling and coding of intonation. Proc. 4th International Conference of Speech Prosody, Campinas, Brazil.
[23] De Jong, N.H. \& T. Wempe (2009). Praat script to detect syllable nuclei and measure speech rate automatically. Behavior Research Methods 41, 385-390.

[24] Boersma, P. (2001). Praat, a system for doing phonetics by computer. Glot International 5, 341-345.

[25] Walker, M.B. \& C. Trimboli (1982). Smooth transitions in conversational interactions. The Journal of Social Psychology $117,305-306$

[26] Heldner, M. (2011). Detection thresholds for gaps, overlaps and no-gap-no-overlaps. Journal of the Acoustical Society of America 130, 508-513.

[27] Niebuhr, O. (2015). Gender differences in the prosody of German questions. Proc. 18th International Congress of Phonetic Sciences, Glasgow, Scotland, 1-5.

[28] Simpson, A. (2009). Phonetic differences between male and female speech. Language and Linguistics Compass 3, 621-640.

[29] Jones, A. E., \& Elliott, M. (2017). Examining social desirability in measures of religion and spirituality using the bogus pipeline. Review of Religious Research 59, 47-64.

[30] Neubauer, R. L. (2014). Prayer as an interpersonal relationship: A neuroimaging study. Religion, Brain \& Behavior 4, 92-103.

[31] Schjoedt, U., Stødkilde-Jørgensen, H., Geertz, A. W., \& Roepstorff, A. (2009). Highly religious participants recruit areas of social cognition in personal prayer. Social cognitive and affective neuroscience 4, 199-207.

[32] Capps, L., \& Ochs, E. (2002). Cultivating prayer. The language of turn and sequence, 39-55.

[33] Carlson, S. M. \& Taylor, M. (2005). Imaginary companions and impersonated characters: Sex differences in children's fantasy play. Merrill-Palmer Quarterly 51, 93-118.

[34] McGuire, D., Chicoine, B. A., \& Greenbaum, E. (1997). Selftalk in adults with Down syndrome. Disability Solutions 2, 1-4. 